\title{
PEMBUATAN MATERI BAHAN AJAR MENGGUNAKAN ANIMASI FLASH BERBASIS MULTIMEDIA UNTUK GURU SMK KARYA UTAMA TANJUNGBALAI
}

\author{
Ada Udi Firmansyah ${ }^{1 *}$, Adi Prijuna Lubis ${ }^{1}$, Raja Tama Andri Agus ${ }^{1}$, Rika Nofitri ${ }^{1}$ \\ ${ }^{1}$ Program Studi Sistem Informasi, STMIK Royal Kisaran, \\ Email : ada_udi_firmansyah@royal.ac.id
}

\begin{abstract}
Teaching media can ease the burden of the teachers, so that the learning process can run well and students can capture and digest the material taught by Master. Therefore, multimedia-based teaching media has an important role in this case, which can help overcome the problems and weaknesses that exist. The software that supports for making this interactive material that is adobe flash is easy to use because of its ability to produce media such as vidio, sound, motion animation, text and images are packaged in a wada that is interactive, keratif and more practical also fun .. the vocational teacher should be able to improve its ability, especially in making the learning media more interactive for students. SMK Karya Utama Tanjung Balai is an education at middle level which prioritizes the development of student skill.
\end{abstract}

Keywords: media teaching, multi media based, adobe flash

\begin{abstract}
Abstrak: Media pembelajaran dapat meringankan beban para pengajar, sehingga proses pembelajaran dapat berjalan dengan baik serta siswa dapat menangkap dan mencerna materi yang diajarkan oleh Guru. Oleh karena itu, media ajar berbasis multimedia memiliki peranan penting dalam hal ini, yaitu dapat membantu mengatasi permasalahan dan kelemahan yang ada. Adapun software yang mendukung untuk pembuatan bahan ajar interaktif ini yaitu adobe flash yang mudah digunakan karena kemampuannya menghasilkan mediaseperti vidio, suara, animasi gerak, teks dan gambar yang dikemas dalam satu wada yang bersifat interaktif, keratif dan lebih praktis juga menyenangkan..Oleh karena itu guru SMK harus mampu meningkatkan kemampuannya terutama dalam pembuatan media pembelajaran yang lebih interaktif bagi siswa.SMK Karya Utama Tanjung Balai merupakan pendidikan pada jenjang menengah yang mengutamakan perkembangan keterampilan siswa
\end{abstract}

Kata kunci : media ajar, berbasis multi media, adobe flash 


\section{PENDAHULUAN}

Pesatnya perkembangan teknologi komputer membuat guru SMK harus dapat menyikapinya dengan bijak. Salah satu bentuk penyikapan yang lazim adalah menggunakan software sebagai media pembelajaran interaktif guna mendukung proses pembelajaran maupun kegiatan pendukungnya.

Media pembelajaran dapat disimpulkansebagai suatu perangkat pembelajaran yang membantu pengajar menyampaikan isi materi ke peserta didik sehingga dapat meningkatkan kualitas proses pembelajaran Reza Pramono. (2014). Dengan adanya media pembelajaran tersebut guru lebih mudah untuk menyapaikan materi kepada peserta didik, dan peserta didik pun lebih mudah untuk menyerap dan memahami materi tersebut, dengan adanya sofware pendukung untuk membuat bahan ajar, para guru diajak untuk membuat bahan ajar yang lebih menarik hingga diminati oleh peserta didik.

Sofware yang digunakan adalah Adobe flash. Jadi Menurut Kumala (2005) Adobe flash ini memiliki kelebihan mampu menyimpan file-file dalam ukuran yang lebih kecil sehingga cukup praktis dan mudah untuk menggunakannya. Oleh karena itu guru SMK harus mampu meningkatkan kemampuannya terutama dalam pembuatan media pembelajaran yang lebih atraktif bagi siswa.

\section{METODE}

\section{Materi Pengabdian Kepada Masyarakat}

Materi pengabdian kepada masyarakat disusun sesuai dengan tujuan yang ingin dicapai diantaranya mengenai : pengenalan aplikasi adobe flash Cs6, mengenal tool dan cara kerja adobe flash Cs6, teknik dasar pembuatan media bahan untuk pembelajaran.

\section{Metode Pengabdian Kepada Masyarakat}

Metode pelaksaan dalam pengabdian masyarakat ini adalah melaksanakan kegiatan pelatihan dalam bentuk tutorial, dengan menjelaskan dasar teori dan praktek langsung

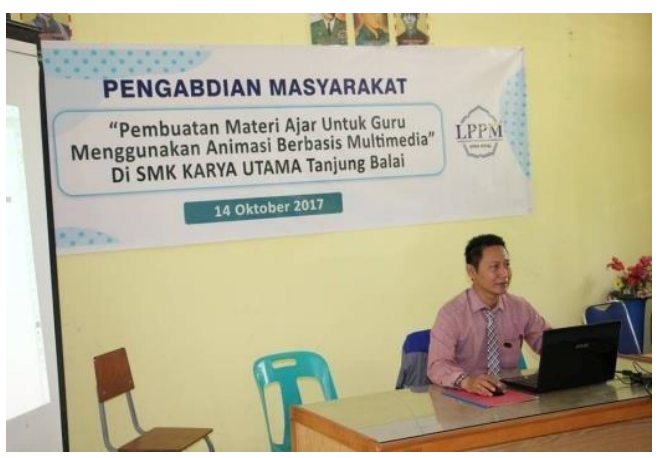

Gambar 11 Menyampaikan materi

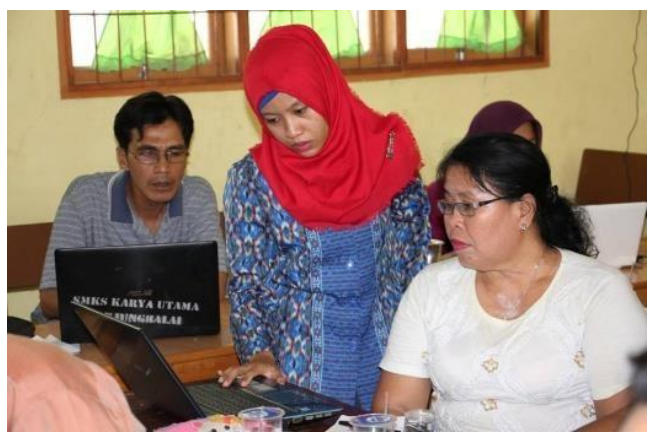

Gambar 12 membantu dalam pelatihan 


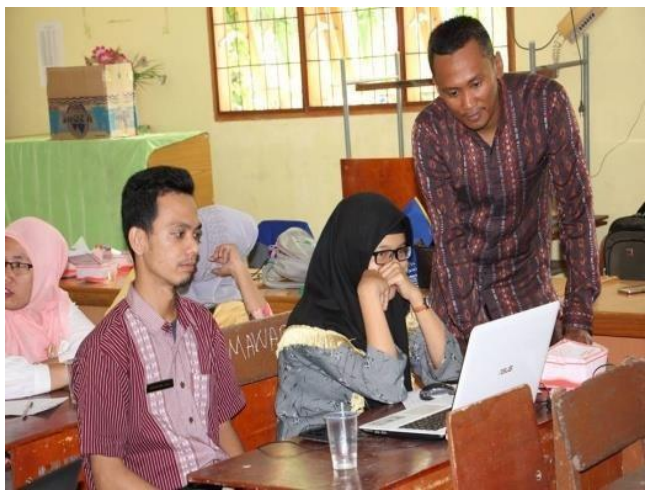

Gambar 13 membantu dalam pelatihan

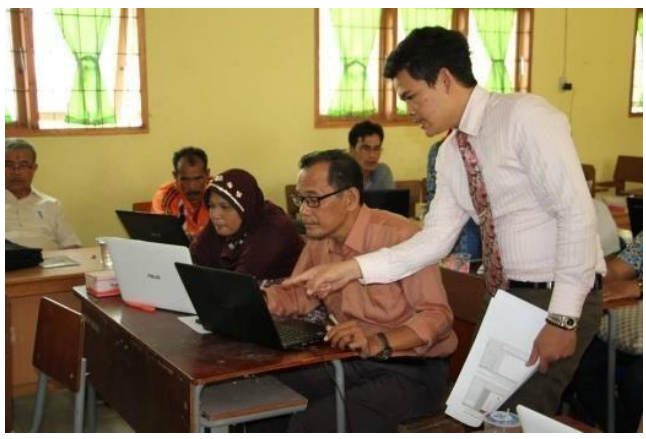

Gambar 14 membatu dalam pelatihan

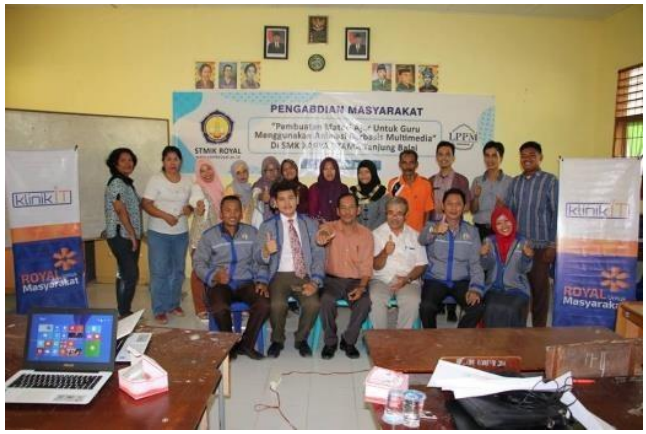

Gambar 15 foto berasama setelah pelatihan

\section{PEMBAHASAN}

Dalam membuat media bahan ajar ada beberapa tahap yang harus anda lakukan terlebih dahulu. Adapun tahaptahap tersebut adalah:
1. Persiapan

Persiapkan terlebih dahulu Laptop atau PC yang diperlukan untuk melakukan penginstalan aplikasi.Lakukan penginstalan aplikasi Adobe Flash Cs6 pada laptop atau PC dengan syarat spek standar media yang memungkinkan.

2. Proses Penginstalan

Memulai penginstalanadobe flash Cs6 samapi instalasi sukses.

3. Pengujian

Saat proses penginstalan telah terselesaikan, maka tahap selanjutnya adalah pengujian. Pada tahap ini laptop atau komputer yang selesai diinstal akan dicoba mengoperasikan Adobe Flash Cs6. Jika pengoperasian berjalan normal maka proses aplikasi adobe flash sudah bisa digunakan, namun apabila ternyata terjadi masalah maka dilanjutkan pada proses yang selanjutnya, yaitu menangani masalah yang terjadi.

4. Penanganan Masalah

Pada tahap ini laptop atau komputer yang selesai diinstal ternyata mengalami masalah (troubleshoot). Hal tersebut bisa disebabkan oleh proses instalasi atau kode crak yang kurang tepat. Oleh sebab itu diperlukan penanganan lebih lanjut agar adobe flash bisa beroperasi dengan normal.

\section{SIMPULAN}

Kesimpulan dari kegiatan pengabdian kepada masyarakat pada SMK Karya Utama kota Tanjung Balai ini adalah : 
Available online at http://jurnal.stmikroyal.ac.id/index.php/jurdimas

1. Bagi seorang guru materi pembelajaran sangatlah penting dan diharuskan.

2. Dengan adanya aplikasi media pembelajaran, tentu sangatlah membantu dan meringankan tugas bagi para guru untuk memberikan materi yang selama ini hanya dengan metode ceramah dan menulis di papan tulis;

3. Tidak semua siswa mempunyai pemikiran yang tanggap dan mempunyai kemauan untuk cepat memahami mata pelajaran yang ada disekolah, tetapi dengan adanya media pembelajaran siswa bisa lebih cepat memahami materi pembelajaran.

4. Kepala Sekolah, Guru bahkan Ketua Yayasan sangatlah antusias, ini semua terlihat dari penyambutan yang serius terhadap kami juga ikut sertanya Kepala Sekolah serta Ketua
Yayasan dalam pelatihan yang kami lakukan.

\section{DAFTAR PUSTAKA}

Arief S Sadiman, dkk 2008 Media pendidikan. Jakarta : PT Raja Grafindo Persada

Khotimah,, 2008 "Media Pembelajaran”. Yogyakarta: CV Andi Offset

Pramono, Reza. 2014. "Penerapan Media Pembelajaran Berbasis Macromedia Flash 8 Untuk Meningkatkan Hasil Belajar Siswa, Surabaya".

Sanjaya, Wina. 2012. Strategi Pembelajaran Berorientasi Standar Proses Pendidikan. Jakarta: Kencana Prenada Media Grup.

Pramono Andi 2014. "Adobe Flash CS3. Yogyakarta: CV Andi Offset. 